\title{
Selenium and Glutathione Peroxidase Activity in Maternal and Cord Plasma and Red Cells
}

\author{
NATHAN RUDOLPH ${ }^{(21)}$ AND SHING L. WONG \\ Department of Pediatrics, Downstate Medical Center, SUNY, Brooklyn, New York, USA
}

\begin{abstract}
Summary
Paired samples of maternal and cord plasma and erythrocytes, as well as samples from nonpregnant adult females, were assayed for selenium and for glutathione peroxidase (GSH-Per) activity. Fetal selenium levels, both in red cells $(0.39 \pm 0.08 \mu \mathrm{g} / \mathrm{ml})$ and in plasma $(0.13 \pm 0.03 \mu \mathrm{g} / \mathrm{ml})$, were significantly lower than the respective levels in either pregnant $(P<0.001)$ or nonpregnant $(P$ $<0.001)$ female adults. GSH-Per activity in fetal red cells $(576$ $\pm 131 \mathrm{U} / 100 \mathrm{ml})$ and plasma $(10.3 \pm 4.0 \mathrm{U} / 100 \mathrm{ml})$ were similarly significantly lower than the respective levels of activity in each group of adult samples $(P<0.001)$. Erythrocyte selenium levels were similar in nonpregnant $(0.52 \pm 0.05 \mu \mathrm{g} / \mathrm{ml})$ and pregnant $(0.52 \pm 0.07 \mu \mathrm{g} / \mathrm{ml})$ adult females; but there was a significant difference in erythrocyte GSH-Per activity between the nonpregnant $(832 \pm 165 \mathrm{U} / 100 \mathrm{ml})$ and the pregnant $(990 \pm 207 \mathrm{U} / 100$ $\mathrm{ml})$ groups $(0.02<P<0.03)$. The plasma levels of selenium in the nonpregnant females $(0.21 \pm 0.03 \mu \mathrm{g} / \mathrm{ml})$ were significantly higher than in the pregnant group $(0.19 \pm 0.03 \mu \mathrm{g} / \mathrm{ml})(0.01<P<0.02)$; similarly, plasma enzyme activity in the nonpregnant group (19.5 $\pm 4.4 \mathrm{U} / 100 \mathrm{ml}$ ) was significantly higher than in the pregnant group $(14.0 \pm 3.2 \mathrm{U} / 100 \mathrm{ml})(P<0.001)$. A close positive correlation was found between selenium levels and GSH.Per activity, both in plasma and in red cells $(r=0.86)$. The mothers' values for enzyme activity and for selenium, both in plasma and in erythrocytes, were almost invariably higher than the comparable values in her own fetus.
\end{abstract}

\section{Speculation}

Selenium has a biologic role as a component of GSH-Per. Low activity of this enzyme in the fetus is probably an adaptation to a low requirement for antioxidant protection. After birth the continuation of the intrauterine developmental phase may contribute in part to the increased oxidant sensitivity of neonatal red cells. Prolonged inadequate dietary intake of selenium, especially in small premature infants, may further increase sensitivity to oxidant stress.

Selenium has been recognized for a number of years as an essential trace metal in animal nutrition, with the intake in herbivora being dependent upon selenium availability from the soil. The metabolic function of selenium and its mechanism of action remained controversial for many years, although it had been proposed that it interacts with vitamin $\mathrm{E}$ and sulfur amino acids in protecting the cell against peroxidative damage $(2,16)$. Rotruck et al. (15) suggested that selenium functions as part of the GSHPer enzyme system, and recent studies by Hoekstra $e t$ al. (8) in the rat and by Flohé et al. (5) on bovine erythrocytes confirmed that selenium is an integral component of purified glutathione peroxidase. Furthermore, animal feeding experiments have demonstrated a good correlation between dietary selenium intake and the activity of GSH-Per in various tissues $(7,11,17)$.

We had previously reported low activity of GSH-Per in the red cells of newborn infants (6). In order to define the normal range of selenium levels and to evaluate whether any correlation exists in the human between selenium and GSH-Per activity, paired samples of maternal and cord erythrocytes and plasma, respectively, were assayed for selenium and for GSH-Per activity.

\section{MATERIALS AND METHODS}

Paired samples of maternal and cord blood were obtained, with maternal consent, at the time of delivery after full term gestation. Blood samples were also taken from healthy house officers, nurses, and laboratory technicians of both sexes. The blood specimens were collected into dry heparinized tubes, samples of which had been checked previously to ensure the absence of any trace amounts of selenium in the anticoagulant.

Red blood cells were separated by centrifugation at $2500 \mathrm{rpm}$ in a Sorvall RC5 refrigerated centrifuge at $2^{\circ}$, and the plasma was removed and frozen for subsequent assay of selenium and of GSH-Per activity. The buffy coat was removed and discarded, and the red cells were washed three times in cold isotonic saline and then resuspended to an hematocrit of approximately $40 \%$. A portion of the red cell suspension was removed for microhematocrit and hemoglobin determinations, and $0.20-\mathrm{ml}$ aliquots were frozen for later determination of selenium content.

The glutathione peroxidase activity of the red cells was assayed in either fresh saline suspensions, or in samples frozen for not more than $24 \mathrm{hr}$, using Whaun and Oski's modification (20) of the method of Paglia and Valentine (12). Enzyme activity was measured at $25^{\circ}$ in a Zeiss PM 6 spectrophotometer and was expressed as units per $100 \mathrm{ml}$ red blood cells, or in some cases as units per $\mathrm{g}$ hemoglobin in addition. One unit was defined as the amount of enzyme that would catalyze the oxidation of $1 \mu \mathrm{mol}$ NADPH under the conditions of this assay. Plasma GSH-Per activity was measured in a similar fashion on either fresh samples or on samples frozen for up to $48 \mathrm{hr}$, utilizing $0.10 \mathrm{ml}$ plasma in a final volume of $3.0 \mathrm{ml}$ reaction mixture. An equilibration time of 20-30 min was generally required before the addition of hydrogen peroxide to initiate the reaction. The results were expressed in units per $100 \mathrm{ml}$ plasma (for comparison with erythrocyte activity). Storage of frozen samples at $-18^{\circ}$ for the periods indicated were shown to have no effect on enzyme activity. Reduced GSH, GSSH reductase (200 units/mg protein $/ \mathrm{ml}$ ), and NADPH were obtained from Sigma Chemical Company (St. Louis, MO). Solutions of GSH $(0.15 \mathrm{M})$ were freshly prepared before each batch of assays from preweighed aliquots of $\mathrm{GSH}$.

The selenium content of the red cell suspension and of plasma were measured on $0.20-\mathrm{ml}$ samples of each by the fluorometric method of Watkinson (19) with slight modifications. Digestion with $2 \mathrm{ml}$ nitric acid (70\%) was allowed to proceed at room temperature for $24 \mathrm{hr}$. Samples were set aside for a further $24 \mathrm{hr}$ after addition of EDTA and hydroxylamine. 2,3-Diaminonaphthalene was used as the complexing reagent and Decalin (decahydronaphthalene) (J. T. Baker Chemical Co., Phillipsburg, $\mathrm{NJ})$ as the extracting solvent for the complex. The fluorescence 
was measured in a Turner fluorometer, model 110 , fitted with a no. 7-60 (369 $\mathrm{nm})$ primary filter and a no. $58(522 \mathrm{~nm})$ secondary filter. The selenium content was expressed as $\mu \mathrm{g} / \mathrm{ml}$, both for plasma and for red cells.

\section{RESULTS}

The level of selenium in cord erythrocytes $(0.39 \pm 0.08 \mu \mathrm{g} / \mathrm{ml})$ was found to be significantly lower $(P<0.001)$ than the level in either maternal erythrocytes $(0.52 \pm 0.07 \mu \mathrm{g} / \mathrm{ml})$ or red cells from nonpregnant, adult female control subjects $(0.52 \pm 0.05 \mu \mathrm{g} / \mathrm{ml})$ (Table 1). No significant difference was noted between the selenium levels in the pregnant females at term and the nonpregnant females, nor was any significant difference noted between healthy male and female adults.

As reported previously $(4,6,19)$, the activity of GSH-Per in cord erythrocytes $(576 \pm 131 \mathrm{U} / 100 \mathrm{ml})$, was also found to be significantly less $(P<0.001)$ than the activity in either maternal erythrocytes $(990 \pm 207 \mathrm{U} / 100 \mathrm{ml})$ or in red cells from nonpregnant adult female control subjects $(832 \pm 165 \mathrm{U} / 100 \mathrm{ml})$. However, in contrast to selenium levels, a comparison of enzyme activity in the latter two groups of pregnant and nonpregnant females showed a slight but significant difference $(0.02<P<$ 0.03 ) (Table 1). Expressing activity as units per $g$ hemoglobin yielded similar results.

In view of the reported association between selenium and GSHPer activity in animal studies $(7,9,11,17)$, a comparison was made between selenium levels and enzyme activity in 24 paired maternal-cord erythrocyte samples together with those from healthy male and female adults. A close correlation $(r=0.86)$ was noted between selenium level and enzyme activity (Fig. l).

In the present study, as in previous investigations $(4,6,20)$, overlap was noted between the lower range of maternal/adult red cell GSH-Per values and the upper range of the cord values (Fig. 1). However, when each mother's red cell enzyme activity was compared with that of her own fetus, the mother's enzyme level was, with only one exception, consistently higher than that of her fetus (Fig. 2).

Similarly, a comparison of the 34 paired maternal and cord red cell selenium levels again showed virtually no overlap of values for each maternal and cord pair, in keeping with the distinct differences noted in the enzyme values (Fig. 3).

The levels of both selenium and GSH peroxidase activity in plasma were considerably lower than their respective levels in erythrocytes (Table 1). As in the red cell, the values of selenium $(0.13 \pm 0.03 \mu \mathrm{g} / \mathrm{ml})$ and of GSH-Per activity $(10.3 \pm 4.0 \mathrm{U} / 100$ $\mathrm{ml}$ ), respectively, in cord plasma were significantly lower than in either maternal plasma or plasma from nonpregnant female adult control subjects. In plasma, however, not only was there a highly significant difference $(P<0.001)$ between the GSH-Per activity of the pregnant and nonpregnant female subjects, but there was also a significant difference $(0.01<P<0.02)$ between the plasma selenium levels of these two groups (Table 1).

A highly significant correlation was noted $(r=0.86)$ between plasma selenium levels and plasma GSH-Per activity (Fig. 4),

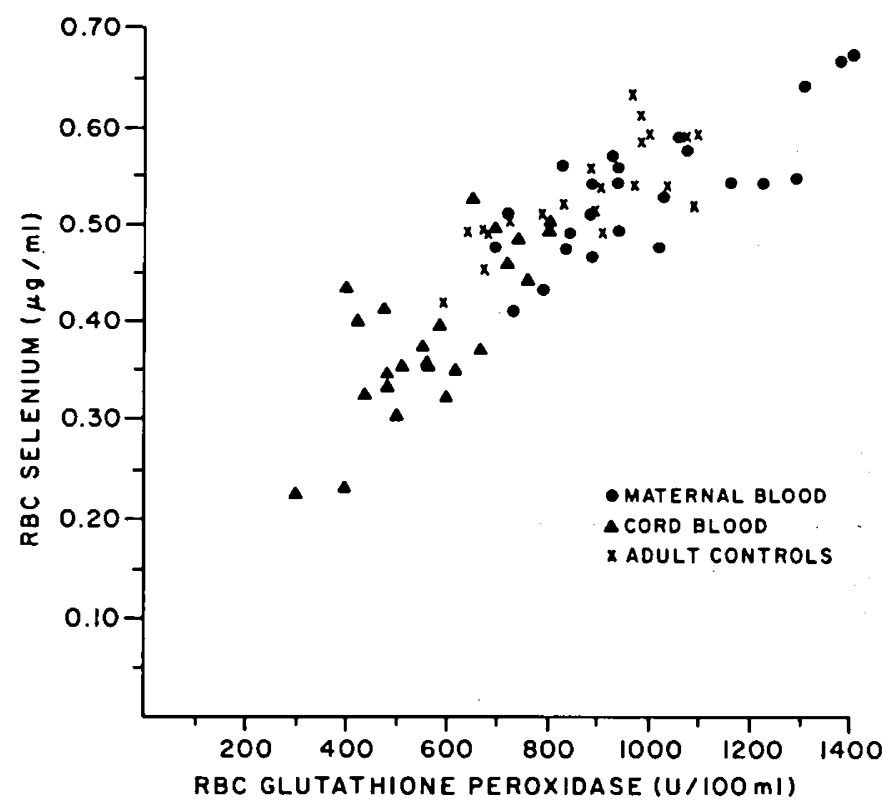

Fig. 1. Correlation between erythrocyte selenium levels and erythrocyte glutathione peroxidase activity in paired maternal/cord samples together with samples from healthy male and female adults $(r=0.86)$.

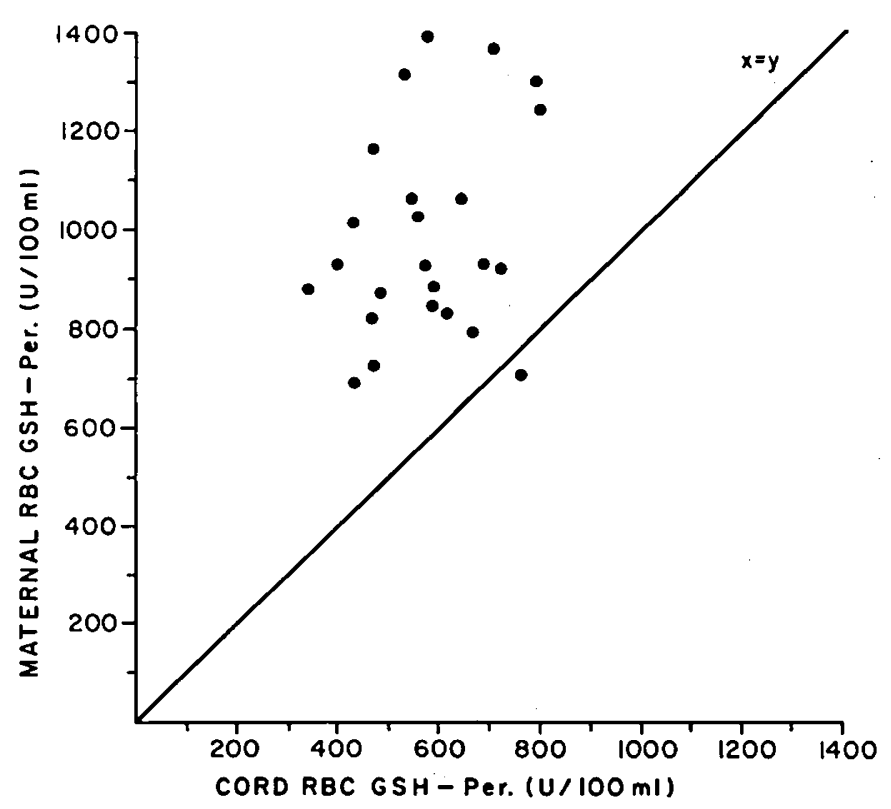

Fig. 2. Erythrocyte GSH-Per activity of maternal blood samples compared with corresponding cord blood samples.

Table 1. Erythrocyte and plasma selenium levels and glutathione peroxidase activity in healthy adult females and in paired samples of maternal and cord blood

\begin{tabular}{|c|c|c|c|c|}
\hline & \multicolumn{2}{|c|}{ Selenium (mean $\pm \mathrm{SD}$ ), $\mu \mathrm{g} / \mathrm{ml}$} & \multicolumn{2}{|c|}{ GSH-Per (mean $\pm \mathrm{SD}$ ), U/100 ml } \\
\hline $\begin{array}{l}\text { Adult females, (nonpreg- } \\
\text { nant) }\end{array}$ & $\begin{array}{r}0.52 \pm 0.05 \cdot(16)^{1} \\
\mathrm{NS}^{2}\end{array}$ & $\begin{array}{r}0.21 \pm 0.03(16) \\
0.01<P<\end{array}$ & $\begin{array}{r}832 \pm 165(16) \\
0.02<P<\end{array}$ & $19.5 \pm 4.4$ \\
\hline Mothers at delivery & $0.52 \pm 0.07(34)$ & $0.19 \pm 0.03$ & $990 \pm 207$ & $\begin{array}{r}14.0 \pm 3.2(13) \\
0.02<P<\end{array}$ \\
\hline
\end{tabular}

\footnotetext{
' Numbers in parentheses indicate number of samples tested.

${ }^{2}$ Statistical significance on Student $t$-test.
} 


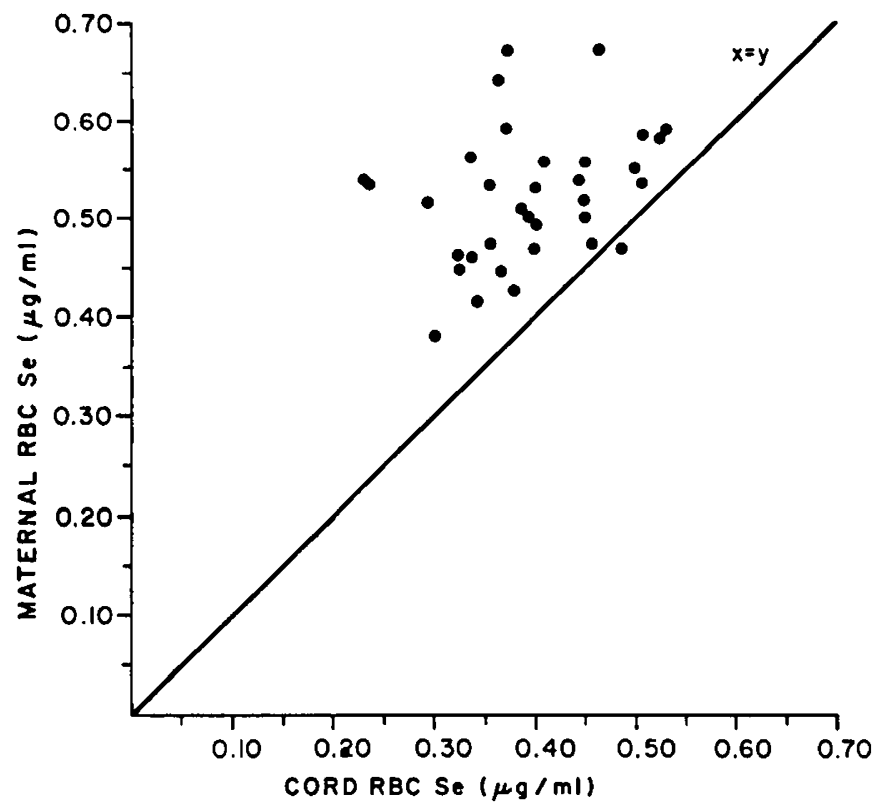

Fig. 3. Erythrocyte selenium levels of maternal blood samples compared with corresponding cord blood samples.

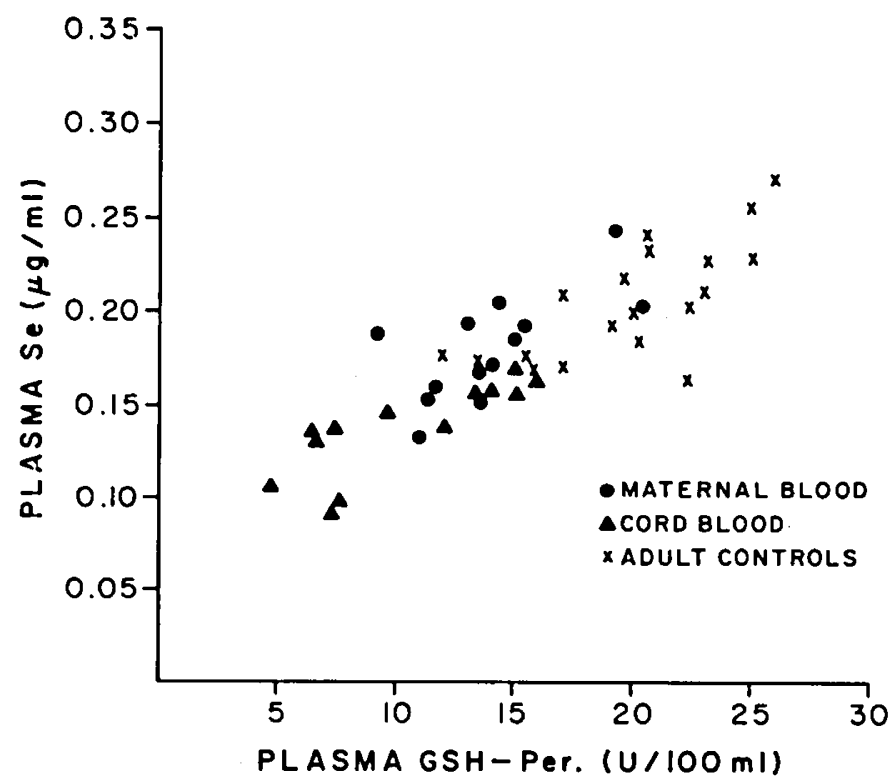

Fig. 4. Correlation between plasma selenium levels and GSH-Per activity in paired maternal/cord samples together with samples from healthy male and female adults $(r=0.86)$.

similar to that observed in the erythrocyte studies. As in the latter data, some overlap was apparent between high cord values and low adult/maternal values. However, when paired samples of maternal and cord plasma were examined for selenium levels (Fig. 5), and for GSH peroxidase activity, respectively, the values for the mother's plasma were almost invariably higher than the comparable values for her own fetus.

\section{DISCUSSION}

The above findings clearly indicate an association between selenium levels and GSH-Per activity in man, and confirm the recent report by Thomson et al. (18), who demonstrated a similar relationship in samples of whole blood. In our study, the correlation was observed both in plasma and in red cells. However, the enzyme activity in plasma is only approximately $1-2 \%$ of that in red cells under similar assay conditions, whereas the level of

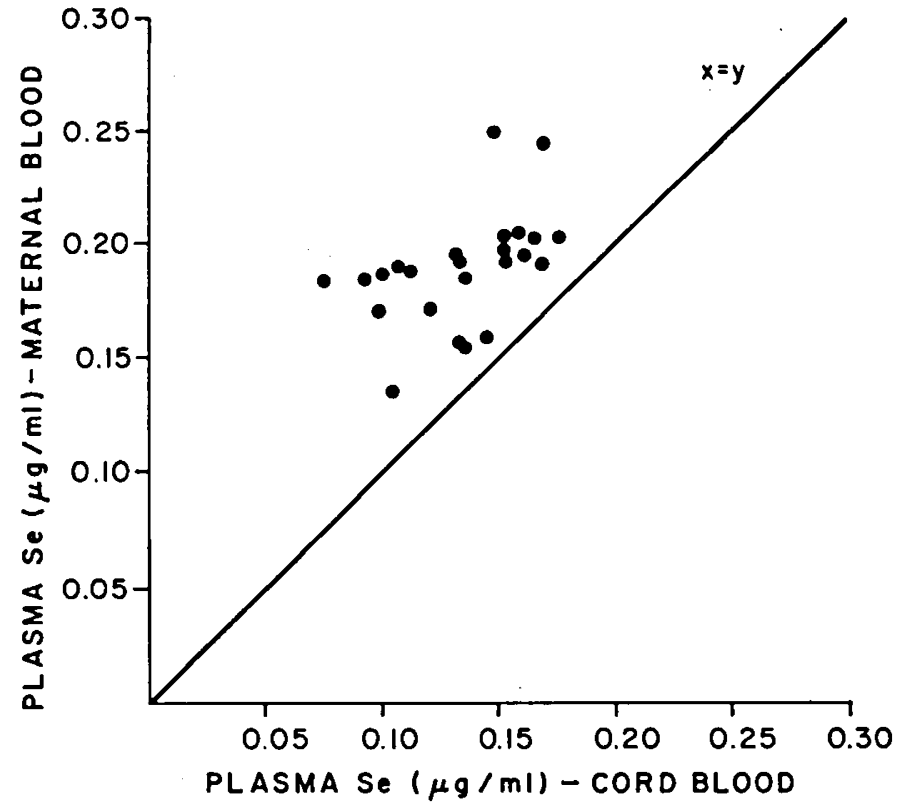

Fig. 5. Plasma selenium levels of maternal blood samples compared with corresponding cord blood samples.

selenium in plasma is about $30-40 \%$ of that in red cells. This suggests that a considerable proportion of the plasma selenium is either not directly associated with GSH-Per, or, alternatively, that the enzyme may be inactivated or inhibited in plasma. Rhead et al. (14) have in fact indicated that selenium is present in a number of human blood plasma fractions, with about $30 \%$ of plasma selenium being dialyzable. In ovine erythrocytes, GSH-Per accounts for about $75 \%$ of the selenium content, and red cells contain a relatively constant proportion of the total blood selenium, even though the latter may vary with different experimental dietary intakes of selenium $(7,8,10)$.

In the present study the correlation between enzyme activity and selenium content, both in plasma and in erythrocytes, was noted in healthy human subjects on a presumably normal diet, in contrast to animal studies in which the dietary selenium content was varied markedly from concentrations of $0.01-0.50 \mathrm{ppm}(10$, $11,17)$. This might tend to suggest that at least some variability of enzyme activity is the result of genetic predisposition. However, it does not exclude the possibility of enzyme variability due to different eating patterns within the same population group, so that individuals may consume varying amounts of foods with a higher, or lower, selenium content.

The lower levels of selenium and of GSH-Per activity in fetal red cells and plasma in comparison with the adult samples is striking, although the underlying controlling mechanisms are not clear. It is possible that placental transport of selenium is limited, with a relatively high maternofetal gradient, so that the concentration of the metal, and hence the activity of the enzyme, is lower in fetal tissues. On the other hand, low enzyme activity in the fetus might represent a phase of development adapted to the low intrauterine oxygen environment, with a decreased need for peroxide detoxification mechanisms, and hence decreased uptake of selenium from maternal plasma. The finding of low GSH-Per activity in neonatal rat liver, and a progressive rise with increasing age (13), would tend to support a developmental mechanism.

The slight, but significant, increase in enzyme activity of maternal erythrocytes as compared to those from nonpregnant females might be the result of an increase in the number of reticulocytes and younger cells (with higher enzyme activity (20)) in the maternal circulation (3). However, further studies would be necessary to confirm this, as well as to explain the lack of a concomitant increase in selenium levels in the maternal erythrocytes.

Very little is known about the absorption and metabolism of selenium in the human, or about the mechanisms that control 
plasma levels. Although it has been suggested that plasma GSHPer is probably synthesized in the liver (11), only a small proportion of the total selenium in plasma is likely to be associated with active enzyme molecules, as discussed previously. In the pregnant female rat, Behne and his coworkers (1) described a decrease in serum levels of selenium during the latter half of gestation, and attributed this to either hormonal influence or changes in carrier protein. However, it is possible that the lower levels of both selenium and enzyme in maternal plasma merely represent dilutional effects associated with the hydremia known to occur during gestation (3), and might not be of any particular significance.

\section{CONCLUSION}

The levels of selenium and of GSH-Per activity were measured in maternal: and cord blood; and were each found to be significantly lower in the fetal samples than in the comparable maternal samples, both in the erythrocyte and in the plasma fractions. It is suggested that low enzyme activity in the fetus might represent a phase of development adapted to the low intrauterine oxygen environment. The study confirms a close positive correlation between selenium levels and GSH-Per activity.

\section{REFERENCES AND NOTES}

1. Behne, D., Elger, W., Schmelzer, W., and Witte, M.: Effects of sex hormones and of pregnancy on the selenium metabolism. Bioinorg. Chem., s: 199 (1976).

2. Bieri, J. G., Dam, H., Prange, L., and Sondergaard, E.: Effect of dietary selenium dioxide, cystine, ethoraquin and vitamin $E$ on lipid autoxidation in chick tissues. Acta Physiol. Scand., 52: 36 (1961).

3. de Leeuw, N. K. M., and Brunton, L.: Maternal hematologic changes, iron metabolism and anemias in pregnancy. In: J. W. Goodwin, J. O. Godden, and G. W. Chance: Perinatal Medicine, p. 425 (The Williams \& Wilkins Co., Baltimore, 1976).

4. Emerson, P. M., Mason, D. Y., and Cuthbert, J. E.: Erythrocyte glutathione peroxidase content and serum tocopherol levels in newborn infants. Brit. J. Haematol., 22: 667 (1972).

5. Flohé, L., Günzler, W. A., and Schock, H. H.: Glutathione peroxidase: A selenoenzyme. FEBS Lett., 32: 132 (1973).

6. Gross, R. T., Bracci, R., Rudolph, N., Schroeder, E., and Kochen, J. A.: Hydrogen peroxide toxicity and detoxification in the erythrocytes of newborn infants. Blood, 29: 481 (1967).

7. Hafeman, D. G., Sunde, R. A., and Hoekstra, W. G.: Effect of dietary selenium on erythrocyte and liver glutathione peroxidase in the rat. J. Nutr., 105: 580 (1974).

8. Hoekstra, W. G., Hafeman, D., Oh, S. H., Sunde, R. A., and Ganther, H. E.: Effect of dietary selenium on liver and erythrocyte glutathione peroxidase in the rat. [Abstr.]: Fed. Proc., 32: 885 (1973).

9. Oh, S. H., Ganther, H. E., and Hoekstra, W. G.: Selenium as a component of glutathione peroxidase isolated from ovine erythrocytes. Biochemistry, 13: 1825 (1974).

10. Oh, S. H., Sunde, R. A., Pope, A. L., and Hoekstra, W. G.: Glutathione peroxidase response to selenium intake in lambs fed a Torula yeast-based, artificial milk. J. Anim. Sci., 42: 977 (1976).

11. Omaye, S. T., and Tappel, A. L.: Effect of dietary selenium on glutathione peroxidase in the chick. J. Nutr., 104: 747 (1974).

12. Paglia, D. E., and Valentine, W. N.: Studies on the quantitative and qualitative characterization of erythrocyte glutathione peroxidase. J. Lab. Clin. Med., 70: 158 (1967).

13. Pinto, R. E., Bartley, W.: The effect of age and sex on glutathione reductase and glutathione peroxidase activities and on aerobic glutathione oxidation in rat liver homogenates. Biochem. J., I12: 109 (1969).

14. Rhead, W. J., Evans, G. A., and Schauzer, G. N.: Selenium in human plasma: Levels in blood proteins and behavior upon dialysis, acidification, and reduction. Bioinorgan. Chem., 3: 217 (1974).

15. Rotruck, J. T., Pope, A. L., Ganther, H. E., Swanson, A. B., and Hoekstra, D. G.: Selenium: Biochemical role as a component of glutathione peroxidase. Science, 179: 588 (1973).

16. Scott, M. L.: Studies on vitamin $E$ and related factors in nutrition and metabolism. In: H. J. DeLuca and J. W. Suttie: The Fat-Soluble Vitamin, p. 355 (The University of Wisconsin Press, Madison, 1969).

17. Smith, P. J., Tappel, A. L., and Chow, C. K.: Glutathione peroxidase activity as a function of dietary selenomethionine. Nature, 247: 392 (1974).

18. Thomson, C. D., Rea, H. M., Doesburg, V. M., and Robinson, M. F.: Selenium concentrations and glutathione peroxidase activities in whole blood of New Zealand residents. Brit. J. Nutr., 37: 457 (1977).

19. Watkinson, J. H.: Fluorometric determination of selenium in biological material with 2,3-diaminonaphthalene. Anal. Chem., 38: 92 (1966).

20. Whaun, J. M., and Oski, F. A.: Relation of red blood cell glutathione peroxidase to neonatal jaundice. J. Pediat., 76: 555 (1970).

21. Requests for reprints should be addressed to: Nathan Rudolph, M.D., Department of Pediatrics, Box 49, Downstate Medical Center, SUNY, 450 Clarkson Avenue, Brooklyn, NY 11203 (USA).

22. Received for publication May $5,1977$.

23. Accepted for publication October 5, 1977. 